\title{
PLANETARY NEBULAE AS A RESEARCH FIELD
}

\author{
W. SAURER and R. WEINBERGER
}

Institut für Astronomie, Universität Innsbruck, Technikerstr. 25, Austria

The "Astronomy and Astrophysics Abstracts", edited twice a year by the "Astronomisches Recheninstitut" in Heidelberg, served as basis for the determination of some data concerning the development of planetary nebulae as a research field. From the numbered and unnumbered papers within the subject category 134 there it was, for example, possible to compare the development of the PN paper rate with that of the whole field of Astronomy; for the years 1986 to 1990, a list (including postal addresses) of all individuals (ca. 900!) who published at least one paper on PN was made. For these 5 years, we now know which scientist(s) published most, in how many countries research on $\mathrm{PN}$ is done, how the annual publication rate varies for a specific country etc. Below, we show two results of our statistics.
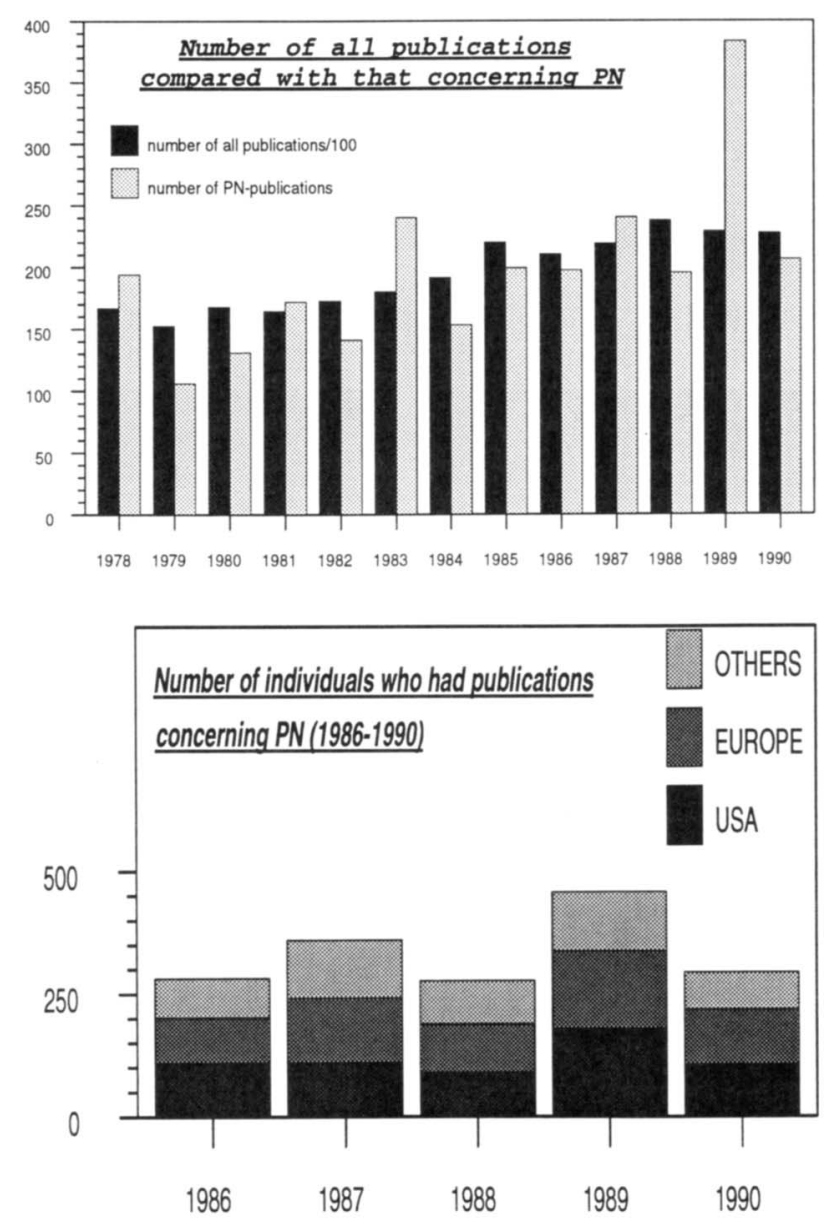